\title{
Carbonized metal-organic frameworks with trapped cobalt nanoparticles as biocompatible and efficient azo-dye adsorbent
}

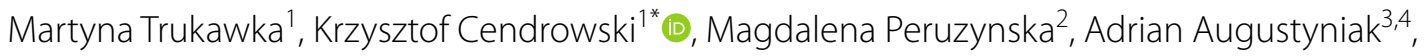
Pawel Nawrotek ${ }^{3}$, Marek Drozdzik² and Ewa Mijowska ${ }^{1^{*}}$

\begin{abstract}
Background: Metal-organic frameworks (MOFs) derived carbonaceous materials functionalized with metal/metaloxide nanoparticles are obtained by its carbonization. The carbonization of MOFs occurs simultaneously with the metal and metal-oxide particle formation. The carbon-based flake-like nanostructures with trapped metal/metaloxide nanoparticles have been formed. Due to its non-toxicity and environmental friendliness, the capacity for pollution adsorption using model anionic dye has been revealed.

Results: The structure of the hybrid is formed as the effect of carbonization of metal-organic frameworks with cobalt as a metal counterpart (CoOF). The cobalt nanoparticles are placed between the carbon layers what limits the dissolution of cobalt nanoparticles and protects the environment from its toxicity. It is preliminary validated by means of two reference micro-organisms (Gram-negative Pseudomonas aeruginosa and Gram-positive Staphylococcus aureus) and in in vitro analysis with human cell line (A375). The efficiency of the adsorption properties of the material was tested with Acid Red 18 as a model anionic dye. The mechanism of dye adsorption was analyzed in details. In addition, various thermodynamic parameters, such as standard enthalpy, standard entropy, and standard Gibbs free energy, were tested. In addition, it was proved that the main substrate of CoOF (terephthalic acid) can be used from PET bottles, while the organic solvent used in its synthesis ( $N, N$-dimethylformamide) was distilled and reused. The obtained carbonized CoOF revealed the same morphology and properties as pristine material.

Conclusions: The kinetic data of dye adsorption fit well with the pseudo-second-order model and Langmuir type. Acid Red 18 adsorption is more favourable at lower temperatures and lower $\mathrm{pH}$. The location of the cobalt nanoparticles between the carbon flakes effectively limits their toxicity compared to the free metal nanoparticles. The CoOF can be obtained from recycled substrates, which revealed the same morphology as pristine material. Therefore, it is believed that this work highlights the practical application of carbonized CoOF as an adsorbate and provides the evidence that such nanocomposite can be applied without environmental risks.
\end{abstract}

Keywords: MOF carbonization, Dye adsorption, Carbonized MOF cytotoxicity, Green synthesis, Cobalt toxicity

\footnotetext{
*Correspondence: kcendrowski@zut.edu.pl; emijowska@zut.edu.pl

${ }^{1}$ Department of Nanomaterials Physicochemistry, Faculty of Chemical

Technology and Engineering, West Pomeranian University of Technology,

Al. Piastów 45, 70-311 Szczecin, Poland

Full list of author information is available at the end of the article
}

\section{Springer Open}

C The Author(s) 2019. This article is distributed under the terms of the Creative Commons Attribution 4.0 International License (http://creativecommons.org/licenses/by/4.0/), which permits unrestricted use, distribution, and reproduction in any medium, provided you give appropriate credit to the original author(s) and the source, provide a link to the Creative Commons license, and indicate if changes were made. 


\section{Background}

Metal-organic frameworks (MOFs) and carbonized MOFs have drawn enormous attention in the last several years $[1,2]$. MOFs are crystalline materials, constructed by joining metal based units (clusters) or metal ions with organic bridging ligands. Using bonds, the organic molecules are held in the place of metal units, creating twoor three-dimensional networks. Self-assemblage network of metal ions/clusters interrelated by organic ligands possess a flexible rational design as a result of the control of the metal and organic ligand type. Pore structure and surface area can be tuned exhibiting high stability and catalytic performance. These crystalline materials are classified as a subclass of coordination polymers with high micropore volume, crystallinity, and a high metal content offering potentially valuable active sites. Therefore, MOFs are promising candidates in the field of clean energy for applications such as hydrogen and gas storage, Li-ion rechargeable batteries, supercapacitors, and solar cells. Moreover, they are also favourable materials for environment protection like dyes and waste adsorption or catalytic waste decomposition. Usually, MOFs are synthesized in hydrothermal conditions using well-soluble salts as the source of metal components and organic molecules-mostly mono-, di-, tri-, and tetracarboxylic acids-as a polar solvent. The properties of crystalline inorganic-organic materials can be adjusted by the carbonization of organic ligands leading to high chemical resistance, large pore volume, high surface area $[3,4]$, as well as catalytic and photocatalytic performance [5]. For that reason, carbon derived of MOFs with metallic or metal-oxide nanoparticles have become attractive materials for catalysis [6], gas adsorption/storage [7, 8], analytical chemistry [9], drug delivery $[10,11]$, and photoluminescence [12].

The carbon-based nanostructures have attracted enormous attention due to its unique physical and chemical properties. Commonly, carbon nanotubes have been used for the dye in its pristine [13] and functionalized form $[14,15]$. Recent studies focus on the different carbon nanostructures, e.g., nanocomposites of ordered mesoporous carbon with ferromagnetic nanoparticles [16], $\mathrm{KOH}$-activated carbon aerogels [17] or graphenebased sandwich-like structures formed by the carboncoating nanoparticles. Such a structure was proposed by Zheng et al. [18]. He proposed one-pot synthesis of sandwich-like MgO@Carbon. Among variety of carbon nanostructures, carbonized carbon such as MOFs focused enormous attention. $[19,20]$.

MOF-derived carbonaceous materials functionalized with metal/metal-oxide nanoparticles can be conveniently prepared the one-step carbonization. The carbonization of MOFs occurs simultaneously with the process of carbon graphitization, growth, agglomeration, as well as oxidation and carboreduction of formed metal oxides to metal particles. The efficiency of these processes is related to the chemical composition of MOFs (type of metal and organic ligand) and the process temperature [21]. Metal nanoparticle in the carbonized structure will be formed in various shapes and sizes with different crystal phases and oxidation degree. The evaporation of metallic particles in the presence of carbon species under an inert gas atmosphere (commonly known as the carboreduction) is responsible for the growth and agglomeration of the nanoparticles. This effect was previously observed by the growth of zinc oxide nanorods during MOF-5 carbonization [22]. The evaporation of the precursor metals varies depending on temperature. Through the control of carbonization parameters, one can design and tune the properties of metal nanoparticles in the MOF-derived carbonaceous materials used for catalysis [23], sensing [24], batteries [25], adsorption [26], and energy storage [27].

Dyes such as Rhodamine B and Acid Reds are widely used in the industrial production of textiles, paper, leather, cosmetics, pharmaceuticals, and food [28]. Azodyes (e.g., Acid Red 18) represent up to $70 \%$ of all dyes being used in the industry. They are the largest, highly water soluble, group among synthetic aromatic dyes used in the textile industry for dyeing. These dyes usually consist of one or more $-\mathrm{N}=\mathrm{N}$-bond, sulfonic $\left(\mathrm{SO}_{3}{ }^{-}\right)$ groups, and complex aromatic molecular structure. Due to the presence of azo groups, they show hepatotoxic effects in albino rats $[29,30]$, and are recalcitrant and carcinogenic in natural environment. The complex aromatic molecular structure is almost non-biodegradable. Therefore, different photo-Fenton and electrochemical oxidation techniques are studied for azo-dye degradation from colored textile wastes [29]. These techniques are expensive and generate amine residues in the sludge after degradation. However, regular consumption of such untreated or poorly treated toxic water shows carcinogenesis in humans [31]. To remove the toxic dyes without their degradation and emission of amine residues, the physical processes can be employed for the purification of dye-contaminating wastewater. Here, adsorption has been recognized as the most promising method for the removal of dyes from aqueous solution due to its simplicity, high efficiency, easy recovery, and reusability of the adsorbent. Up to now, numerous types of adsorbents, such as carbon-based materials (e.g., activated carbon), minerals (e.g., zeolite), and polymeric materials (e.g., polystyrene) for removal of azo-dye from wastewater, were investigated. However, low adsorption capacities of these conventional adsorbents toward dyes restrict their practical applications [30]. 
Shi et al. showed the potential of cobalt oxide nanoparticles located on the surface of graphene oxide in the catalytic decomposition of dye. Shi et al. revealed that graphene oxide (GO) with $\mathrm{Co}_{3} \mathrm{O}_{4}$ was efficient in degradation of Orange II [32]. The catalytic decomposition of dye was performed with the use of advanced oxidation technology based on sulphate radicals. This demonstration showed a synergistic catalysis of the composite. The synergistic catalysis effect, achieved by combination of graphene oxide and cobalt oxide, was proved and analyzed in detail in series of reports of Shi et al. [32, 33]. Many investigators have studied various techniques for the removal of dyes from wastewater, including diversified advance oxidation processes [34], chemical coagulation/flocculation [35], nanofiltration [36], ozonations [37], micellar enhanced ultrafiltration [38], adsorption onto bentonites [39], or several types of activated carbon [40].

Cobalt is an element that naturally occurs in numerous chemical forms. It is a microelement and may be used in cells as a cofactor in enzymes. For that reason, small amounts of cobalt are essential to maintain homeostasis. On the other hand, excessive exposure to cobalt causes a set of neurological, cardiovascular, and endocrine deficits, directly related to the uptake of Co ions [41]. Cobalt compounds can produce carcinogenic effects in humans, which were reported by the International Agency for Research on Cancer. According to the report, cobalt nanoparticles cause changes in gene expression, apoptosis, oxidative stress, and inflammation in the human body [42]. The toxicity of cobalt nanoparticles on plant seeds was also confirmed. Described investigations included mitotoxic and genotoxic effects which lead to the disturbances in mitotic behavior of cells through various types of chromosomal aberrations [43]. The reports indicate that the addition of small amounts of cobalt stimulated microbial growth, which is consistent with its biological role as an enzymatic cofactor. For example, small amounts of cobalt (with $300 \mathrm{mg}(\mathrm{Co}(\mathrm{II})) \mathrm{L}^{-1}$ ) added to the culture of Streptomyces coelicolor A3(2) increased its growth by $~ 50 \%$ [44]. On the other hand, in the current state of art, the effects of cobalt on micro-organisms confirm that high concentrations inhibit microbial growth, although a number of environmental factors (e.g., $\mathrm{pH}$, medium composition, biomass concentration, and presence of other heavy metals) can also affect the toxicity [45]. Research by Adiga et al. [46] indicated that approximately $110 \mathrm{mg}(\mathrm{Co}(\mathrm{II})) \mathrm{L}^{-1}$ reduced by $50 \%$ the growth and glucose consumption of fungus $A$. niger. Al-Sarrani [47] reported that the growth of another fungus, Monoascus rubber, was inhibited by approximately $40 \%$ in the presence of $10 \mathrm{mg}(\mathrm{Co}(\mathrm{II})) \mathrm{L}^{-1}$, whereas minimal inhibitory concentration (MIC) was observed at 100-200 mg
(Co(II)) $\mathrm{L}^{-1}$. Nonetheless, the cobalt nanoparticles are necessary to remove the carbonized MOF structures after dye and impurities adsorption. Therefore, successful entrapment of cobalt nanoparticles in nanostructures is essential to avoid unpredictable biological effects of the nanomaterial.

In this study, we have explored the application of flakelike nanocomposite composed of cobalt nanoparticles trapped between the carbon layers used as anionic dye adsorbent. We reveal the influence of temperature, initial dye concentration, and $\mathrm{pH}$ on the adsorption kinetics. Moreover, cytotoxicity of $\mathrm{CoOF}$ was examinated on the two reference micro-organisms (Gram-negative Pseudomonas aeruginosa and Gram-positive Staphylococcus aureus) and in in vitro analysis with human cell line (A375). Furthermore, synthesis of CoOF structures from recycled and reused substrates was also conducted.

\section{Experimental \\ Materials}

Hydrochloric acid (36\%, CAS Number: 7647-01-1) and $\mathrm{N}, \mathrm{N}$-dimethylformamide (DMF, CAS Number: 68-122) were purchased from Chempur (Poland). The Acid Red 18 (75\%, CAS Number: 2611-82-7), Cobalt chloride $\left(\mathrm{CoCl}_{2}\right.$, CAS Number: 7646-79-9), and terephthalic acid $\left(\mathrm{C}_{6} \mathrm{H}_{4}(\mathrm{COOH})_{2}\right.$, CAS Number: 100-21-0) were bought from Sigma-Aldrich (Germany).

\section{Synthesis and carbonization of cobalt organic framework (CoOF)}

$\mathrm{CoOF}$ was synthesized in the following the procedure. Briefly, $574 \mathrm{mg}$ of terephthalic acid and $740 \mathrm{mg}$ of cobalt (II) chloride $\left(\mathrm{CoCl}_{2}\right)$ were dissolved in $183 \mathrm{~mL}$ of DMF solution. After vigorous stirring, the homogeneous mixture was refluxed at $125^{\circ} \mathrm{C}$ for $24 \mathrm{~h}$. The product was collected by centrifugation ( $8000 \mathrm{rpm}$ for $10 \mathrm{~min}$ ). Obtained CoOF nanocomposite was placed in a horizontal oven and carbonized at $600{ }^{\circ} \mathrm{C}$ for $5 \mathrm{~min}$ in the inert gas atmosphere. $\mathrm{CoOF}$ was placed for purification in a glass flask with chloric acid (36\%) and stirred for $24 \mathrm{~h}$.

$\mathrm{CoOF}$ structures from recycled organic substrates were synthesized from polyethylene terephthalate (PET) bottle and DMF used in the pristine CoOF. To convert the waste PET bottle into the terephthalic acid, polymer bottle was cut into small pieces (approximately $0.5 \times 0.5 \mathrm{~cm}$ ). $10 \mathrm{~g}$ of the bottle flakes was placed with $100 \mathrm{~mL}$ water in the autoclave. The autoclave was then heated up to $150{ }^{\circ} \mathrm{C}$ for $24 \mathrm{~h}$. Obtained white powder was washed with water and dried. DMF after synthesis of $\mathrm{CoOF}$ and centrifugation (8000 rpm for $10 \mathrm{~min}$ ) was refluxed under reduced pressure at $150{ }^{\circ} \mathrm{C}$, with an additional flask to collect the distillate to be reused. The synthesis of CoOF occurred 
according to the method and parameters described above.

\section{Material characterization techniques}

The CoOF morphology was investigated by scanning electron microscopy (TESCAN, VEGA SBU3), under $30 \mathrm{kV}$ acceleration voltage. The $\mathrm{N}_{2}$ adsorption/desorption isotherms were acquired at liquid nitrogen temperature (77 K) using a Quadrosorb SI (Quantachrome Instruments). The specific surface area and pore size distribution were calculated using the Brunauer-Emmett-Teller (BET) method. The crystallographic phases were identified using X'Pert Philips PROX-ray diffractometer (X'Pert PRO Philips diffractometer, CoKa radiation). Thermogravimetric analysis was performed using DTA-Q600 SDT TA instrument with a heating rate of $10{ }^{\circ} \mathrm{C} \mathrm{min}^{-1}$. The dye concentration was examined with the UV-Vis spectrophotometer Helios alpha (Thermo Scientific).

\section{Adsorption, reusability, and regeneration of CoOF}

Dye solution $(10 \mathrm{~mL})$ with initial concentration of 25 , 50,75 , and $100 \mathrm{mg} \mathrm{L}^{-1}$, respectively, was transferred to a conical flask. Afterwards, the flasks were placed on a hotplate, with magnetic stirrer in the water bath to keep constant temperature. The experiments were carried out at 30,40 , and $60{ }^{\circ} \mathrm{C}$, respectively. After the temperature was reached, $10 \mathrm{mg}$ of CoOF was added into the flask. $2 \mathrm{~mL}$ sample was taken from the solution at set time. The liquid was separated with magnet. The concentration of dye was determined spectroscopically at its maximal absorbance (for Acid Red 18 at $508 \mathrm{~nm}$ ). The equation for the adsorption capacity at equilibrium $q_{\mathrm{e}}$ point is provided in Additional file 1.

To determine the reusability of the adsorbent, carbonized $\mathrm{CoOF}$ without regeneration was introduced to the dye solution and maintained for $500 \mathrm{~min}$. All reusability experiments were performed at $20{ }^{\circ} \mathrm{C}$, with dye and nanomaterial concentration equal to $25 \mathrm{mg} \mathrm{mL}^{-1}$ and $1 \mathrm{mg} \mathrm{mL}^{-1}$, respectively. After adsorption the nanomaterial was separated from the solution with the magnet and dried at $60^{\circ} \mathrm{C}$. Powdered samples were divided into two batches that were used for the dye release and further adsorption experiments. All experiments were performed at the same parameters (time, temperature, and CoOF concentration) as the adsorption experiments (described above).

CoOF adsorbent was regenerated at ambient temperature by the insertion of sodium hydroxide $\left(1 \mathrm{mg} \mathrm{mL}^{-1}\right)$ into the nanomaterials. The CoOF $\left(1 \mathrm{mg} \mathrm{mL}^{-1}\right)$ was kept in the solution for $2 \mathrm{~h}$. CoOF after sodium hydroxide treatment was rinsed four times with distilled water and dried at $60^{\circ} \mathrm{C}$.

\section{Cytotoxicity on microbial models}

Microbiological studies were conducted on two reference bacterial strains-Gram-negative Pseudomonas aeruginosa $\mathrm{ATCC}^{\circledR} 27583^{\mathrm{TM}}$ and Gram-positive Staphylococcus aureus $\mathrm{ATCC}^{\circledR} 6538^{\mathrm{TM}}$. Bacteria were kept frozen in Tryptone Soy Broth (TSB, Graso Biotech) medium with $10 \%$ addition of glycerol until used in the experiments. Thawed cultures were streaked to Tryptone Soy Agar (TSA, Graso Biotech) medium and incubated at $37^{\circ} \mathrm{C}$ to obtain the colonies. Afterwards, one colony was taken and inoculated into $25 \mathrm{~mL}$ of TSB medium in a sterile $50 \mathrm{~mL}$ falcon tube and cultured overnight at $37{ }^{\circ} \mathrm{C}$ on rotary shaker.

Toxicity of the studied nanomaterials was tested on 96-well microtiter plates in 24-h assay. Two methods were used for the evaluation-optical density (OD) measurements and alamarBlue ${ }^{\circledR}$ assay (Thermo Fisher Scientific, USA). Each sample was prepared in eight repetitions. The stock samples $\left(1 \mathrm{mg} \mathrm{mL}^{-1} ; 1 \mathrm{~mL}\right.$ each $)$ were sonicated in $1.5 \mathrm{~mL}$ Eppendorf-type tubes in a water bath sonicator (Bandelin Sonorex DT $255 \mathrm{H}$, power-640 W) for $30 \mathrm{~min}$, and then diluted to reach desired concentrations. Carbonized CoOF were suspended in ultrapure water with addition of $1 \%$ dimethyl sulfoxide (DMSO, Sigma-Aldrich, Germany) to obtain four final concentrations $-100 \mu \mathrm{g} \mathrm{mL}-1,50 \mu \mathrm{g} \mathrm{mL}^{-1}, 25 \mu \mathrm{g} \mathrm{mL} \mathrm{m}^{-1}$, and $12.5 \mu \mathrm{g} \mathrm{mL}{ }^{-1}$. The control sample was filled with equal amount of ultrapure water with $1 \%$ DMSO. Additional controls were conducted to confirm that DMSO had not been noxious to the used micro-organisms, and it was introduced into the experimental setting to increase the dispersion of the nanomaterial. Furthermore, the experiments were conducted in triplicate to confirm the gained tendencies. In the final form, each prepared well contained $160 \mu \mathrm{L}$ medium, $20 \mu \mathrm{L}$ CoOF suspension and $20 \mu \mathrm{L}$ of overnight bacterial culture diluted 1:200. Subsequently, optical density (OD) was measured on spectrophotometer Tecan m200 PRO (Männedorf, Switzerland) at $600 \mathrm{~nm}$ wavelength. Afterwards, the plates were kept at $37^{\circ} \mathrm{C}$ without the access of light for $24 \mathrm{~h}$, with shaking $(140 \mathrm{rpm})$ on orbital shaker incubator (Biosan ES-20/60, Latvia). Afterwards, another round of OD measurements was performed. Then, alamarBlue ${ }^{\circledR}$ assay was performed according to the manufacturer's guidelines. For that purpose, $20 \mu \mathrm{L}$ of working solution was added to each well, and then, plates were incubated for $30 \mathrm{~min}$ for $S$. aureus and $2 \mathrm{~h}$ for $P$. aeruginosa without the access of light. After incubation, fluorescence $\left(\lambda_{\mathrm{ex}}=520 \mathrm{~nm} ; \lambda_{\mathrm{em}}=590 \mathrm{~nm}\right)$ was measured with spectrophotometer Synergy HTX (Biotek, USA). The results were analyzed by one-way ANOVA. $P$ values lower than 0.05 were considered as statistically significant. Analyses were performed with Origin 8 (OriginLab) software. 


\section{Cell culture and cytotoxicity assay}

Human malignant melanoma cells (A375, catalogue no. 88113005) were purchased from the European Collection of Authenticated Cell Cultures (ECACC). Cells were cultured in a humidified incubator $\left(5 \% \mathrm{CO}_{2}, 37^{\circ} \mathrm{C}\right)$ in DMEM culture medium (Dulbecco's Modified Eagle Medium, High Glucose, HyClone, Germany) supplemented with $10 \%$ heat-inactivated foetal bovine serum (FBS, HyClone, Germany), L-glutamine (2 mM, SigmaAldrich, Germany), and $0.4 \%$ penicillin-streptomycin (Sigma-Aldrich, Germany).

The cytotoxicity of the reference cobalt nanoparticles (nanoCo) and carbonized CoOF was evaluated using the WST-1 assay (Sigma-Aldrich, Germany). The WST-1 test is based on the reduction of the tetrazolium salt WST-1 to a soluble red formazan by mitochondrial dehydrogenase. The amount of formazan dye is directly correlated to the number of metabolically active cells. In the current study, A375 cells were seeded in 96-well plates $\left(3 \times 10^{3}\right.$ cells/well in $100 \mu \mathrm{L}$ medium). After $24 \mathrm{~h}$, the culture medium was removed and the cells were treated with carbonized $\mathrm{CoOF}$, and dispersed in the cell culture medium to reach the concentrations of 100,50 , and $25 \mu \mathrm{g} \mathrm{mL} \mathrm{L}^{-1}$. The reference cobalt nanoparticle samples were dispersed in a medium to reach concentrations equal to Co concentrations in the carbonized samples, namely: 55 , 27.5, and $13.75 \mu \mathrm{g} \mathrm{mL}^{-1}$ for carbonized CoOF. All samples were vortexed and sonicated (not longer than $1 \mathrm{~min}$ ) before application to the cell medium. The cells without the tested compounds were used as controls. After $48 \mathrm{~h}$, WST-1 reagent was added and incubated with the cells for $30 \mathrm{~min}$. Absorbance was measured at $450 \mathrm{~nm}$ (with $620 \mathrm{~nm}$ background correction), using a spectrophotometric microplate reader (Infinite 200 Pro, Tecan, Switzerland). The interaction between compounds (without cells) and WST-1 reagents was also determined $\left(A_{\text {blank }}\right)$. The results were normalized to the control cells, and the cell viability was calculated using the following formula: the number of viable cells (\% of control $)=\left[\left(A_{\text {test }}-A_{\text {blank }}\right) /\right.$ $\left.\left(A_{\text {control }}-A_{\text {blank }}\right)\right] \times 100 \%$. The readings were acquired from three independent experiments (each conducted in triplicate). Statistical analysis was performed using Statistica 12 software (StatSoft Inc., Tulsa, Oklahoma, USA). The results were expressed as mean \pm standard deviation. Experimental data were analyzed by Student's $t$ test. The criterion for statistical significance was set at $P<0.05$.

\section{Results and discussion}

\section{Characterization of the carbonized material}

SEM images of the morphology of pristine CoOF are shown in Fig. 1a. The particles exhibited hexagonal shape in range $5-20 \mu \mathrm{m}$. During the carbonization, organic ligand graphitization and cobalt nanoparticle oxidation occurred. Carbonized CoOF crystals maintained their original hexagonal-like shape and were covered with cobalt oxides nanoparticles (see Fig. 1b). Figure 1c shows the flakes of carbonized CoOF after removal of Co with chloride acid. However, the Co species were visible on both samples as brighter spots and were distributed allover the hexagonal-like structures. The encapsulation of Co inside carbonized CoOF was reported previously [48]. The presence of cobalt species (as cobalt and cobalt oxide presented in Fig. 1d) in the carbonized CoOF has been confirmed by XRD. The Brunauer-Emmett-Teller method (BET) revealed that the surface area of carbonized CoOF is $199 \mathrm{~m}^{2} \mathrm{~g}^{-1}$. The carbonized CoOF pore volume reached $0.812 \mathrm{~cm}^{3} \mathrm{~g}^{-1}$ with the average pore radius at $8.142 \mathrm{~nm}$. The nitrogen adsorption isotherm of carbonized CoOF sample is presented in Additional file 1: Figure $\mathrm{S} 1$ and it can be described as a Type IV isotherm, which is characteristic for the mesoporous structure [49].

The TGA curves of carbonized CoOF showed a mass loss in two stages (Fig. 1e). The first mass loss started at $380{ }^{\circ} \mathrm{C}$, and corresponded to the removal of oxygencontaining functional groups ( $10 \mathrm{wt} \%$ of the sample). The second mass loss (starting at $420{ }^{\circ} \mathrm{C}$ ) corresponded to the pyrolysis of the carbon material. TGA analysis also showed that the content of the metal nanoparticles in the carbonized CoOF was $\sim 50 \mathrm{wt} \%$ of the sample. To prove the efficiency of encapsulation cobalt particles between the graphene layers, atomic adsorption spectroscopy was used. The carbonized CoOF with $50 \mathrm{wt} \%$ of cobalt (as a metallic cobalt and oxides) at concentration $1 \mathrm{~g} \mathrm{~L}^{-1}$ released up to $40 \mu \mathrm{g} \mathrm{L}^{-1}$, during first $48 \mathrm{~h}$ (Fig. 1f). This is less than $1 \mathrm{wt} \%$, proving that graphene layers protect cobalt particles from dissolution. Detailed physicochemical analysis of the pristine and carbonized material was presented previously $[48,50]$.

\section{Adsorption kinetics, adsorption isotherms, effect of temperature, and $\mathrm{pH}$}

The sorption kinetics was conducted to elucidate the mechanism that controls the dye sorption process. It is well known that the process parameters played an imperative role in the adsorption processes by the influence on the physicochemical nature of the adsorbate-adsorbent, and in a consequence through the control in the removal rate. Therefore, the interpretation of sorption kinetics data in terms of various process parameters including $\mathrm{pH}$, temperature, and initial dye concentration provides valuable insights of the sorption mechanism.

Acid Red 18 adsorption experiments were performed with initial dye concentrations ranging between 10 and $25 \mathrm{mg} \mathrm{L}^{-1}$ at $\mathrm{pH}$ of 7 at $20^{\circ} \mathrm{C}$. Acid Red 18 adsorption increased from $23.5 \mathrm{mg} \mathrm{L}^{-1}$ to $41 \mathrm{mg} \mathrm{L}^{-1}$ along with the increase in dye concentration (Fig. 2a). There was a rapid 

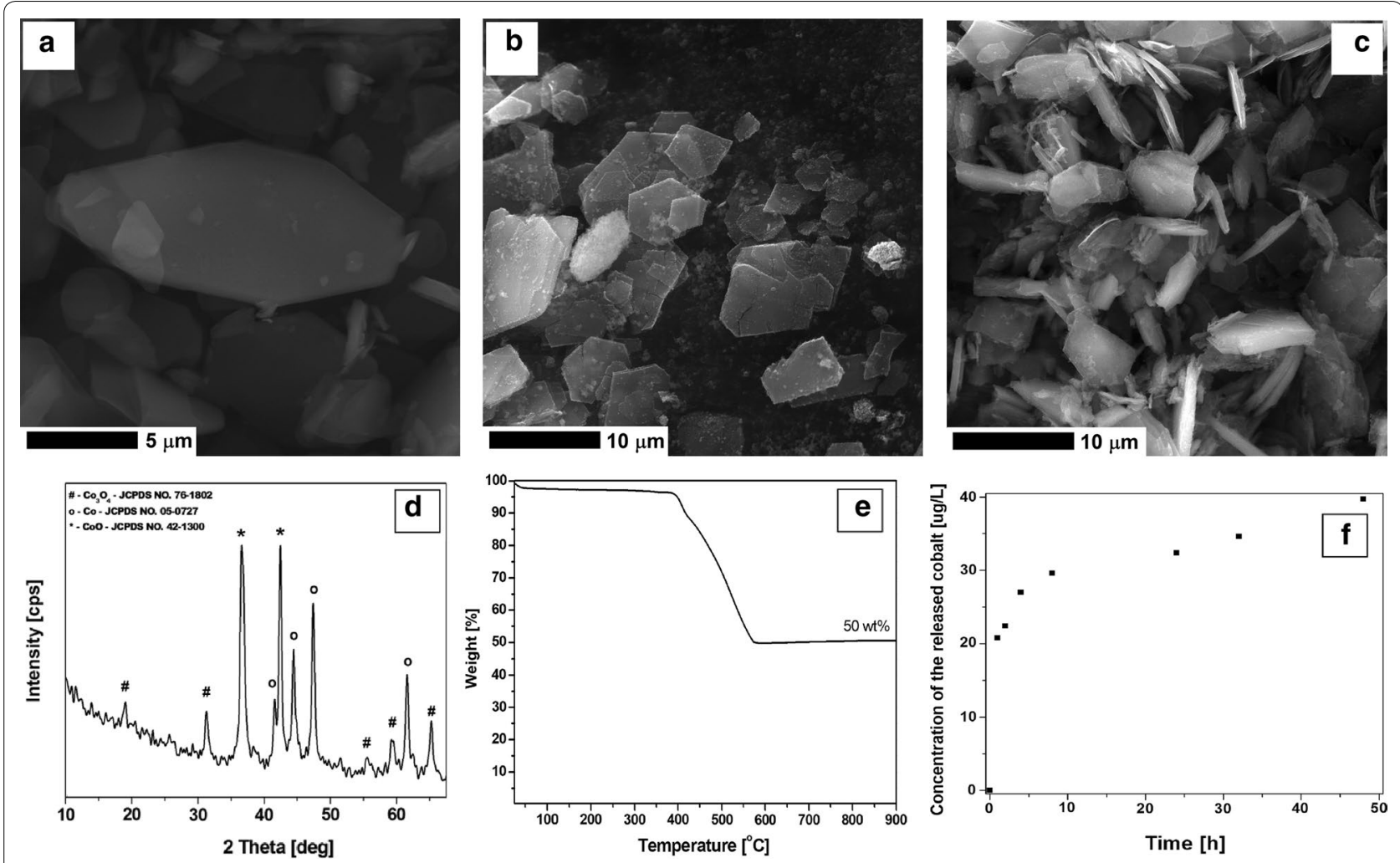

Fig. 1 SEM images of COOF (a) and carbonized CoOF before (b) and after (c) acid purification. X-ray diffraction spectra (d), TGA (e), and amount of released cobalt particles $(\mathbf{f})$ from the carbonized and purified CoOF
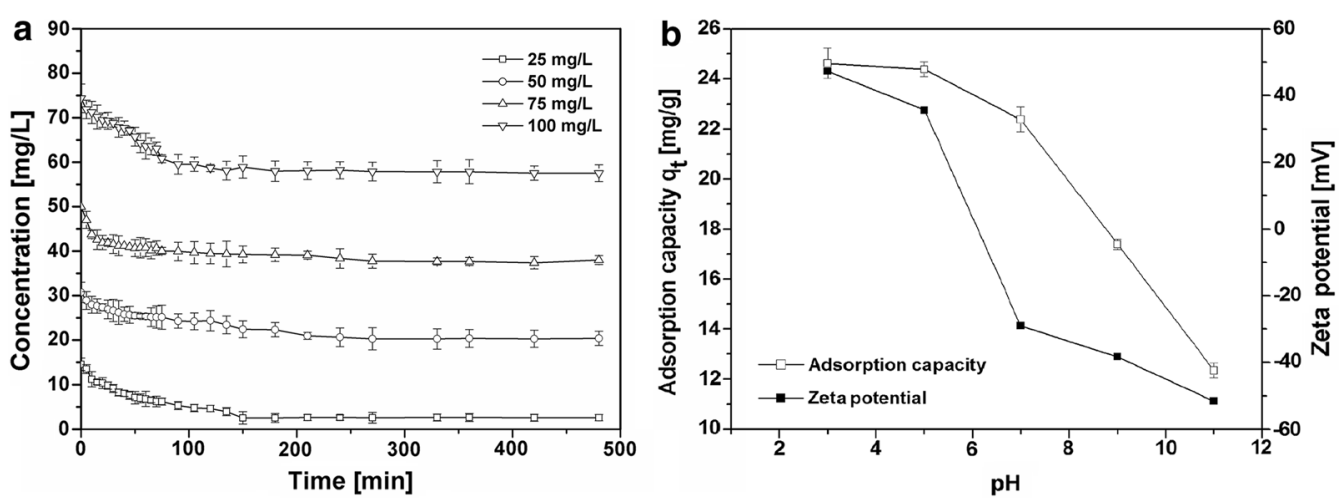

Fig. 2 The effect of initial dye concentration (a) and pH (b) on the adsorption capacity of the AR18 onto carbonized CoOF and zeta potential changes

increase in the adsorption capacity for the first 10 min of contact for all concentrations which then proceeded in a slower rate, until it reached the equilibrium point. The time needed to reach the equilibrium point was reduced after the increase of the dye concentration. The highest correlation coefficients were observed for the pseudosecond-order kinetic model. The correlation coefficient of intraparticle diffusion kinetic model $\left(R^{2} \leq 0.828\right)$ was lower than calculated pseudo-second-order kinetic model (see Additional file 1: Figure S1 and Table S1). This suggested that the pseudo-second-order adsorption mechanism had been predominant [51].

The theoretical model proposed by Weber and Morris states that the adsorption process is controlled solely by 
the intraparticle diffusion if the regression of $q_{\mathrm{t}}$ versus $t_{0.5}$ is linear and passes through the origin. Equation for the intraparticle diffusion calculation with plots (Additional file 1: Figure S3) is presented and described.

All equations used for the calculation of adsorption isotherms are provided Additional file 1. Both isotherm plots and data of the fitted models with correlation coefficients $R^{2}$ are given in Additional file 1: Figure S3 and Table S2. Obtained results indicated that the adsorption processes could be well fitted by the Langmuir isotherm model, and suggesting that maximum adsorption corresponds to the formation of AR18 monolayer on CoOF. According to the Langmuir isotherm model, the energy of adsorption is constant and the adsorbate does not transmigrate to the surface.

The effect of temperature on equilibrium adsorption was examined to determine whether the process was endothermic or exothermic. The adsorption capacities of AR18 decreased with increase in the temperature. The calculated thermodynamic parameters and all equations used for the calculation of thermodynamic parameters are listed in Additional file 1: Table S3 and Figure S4.

The negative value of enthalpy $\left(\Delta H^{\circ}\right)$ $\left(-105.23 \mathrm{~kJ} \mathrm{~mol}^{-1}\right)$ indicates that AR18 was adsorbed onto $\mathrm{CoOF}$ in the exothermic reaction [52]. Negative value of $\Delta S$ indicated a decrease in the degrees of freedom during the adsorption. Before adsorption molecules can move in three dimensions, although when they are being adsorbed on the surface, the motion of molecules is restricted towards the surface and their entropy decreases. This phenomenon is characteristic for the adsorption by the metal-organic frameworks [53]. The positive Gibbs energy $\left(\Delta G^{\circ}\right)$ values indicate that there is an energy barrier and the reaction should not occur or the opposite reaction could occur-desorption (slight decrees of absorption capacity after $60 \mathrm{~min}$.). The calculated thermodynamic parameters are listed in Additional file 1: Table S3 and Figure S4). The pseudo-second-order model along with free Gibbs energy suggests that for the studied temperatures, physisorption took place.

The effect of $\mathrm{pH}$ has an important influence on the adsorption process. Therefore, the influence of $\mathrm{pH}$ of the solution on the adsorption of AR 18 onto CoOF was analyzed. The $\mathrm{pH}$ of the solutions were adjusted by addition of $0.1 \mathrm{M} \mathrm{HCl}$ or $\mathrm{NaOH}$. As presented in Fig. 2, pH of solution alters the CoOF adsorption capacity. An adsorption capacity was decreased with increasing in $\mathrm{pH}$. The adsorption capacity is the highest at $\mathrm{pH}<5$ and stabilizes above this value. The analysis of the zeta potential of the absorbent allowed to determine the surface charge of CoOF. The surface charge decreases from the positive value to the negative with increase in $\mathrm{pH}$, reaching zero net charge at $\mathrm{pH}=6.5$.
AR18, as the anionic dye, dissociates to sodium cations and sulphur anions in acid aqueous solution. Positive charges on CoOF surface (at $\mathrm{pH}$ below 6.5) enhance the adsorption of anionic dye through electrostatic interaction. Figure 2 shows that zeta potential and adsorption capacity are correlated with each other.

The FT-IR spectra of the sample after dye adsorption in the $\mathrm{pH}$ range from 3 to 11 are presented in Additional file 1: Figure S5.

The adsorption on the carbon nanomaterials follows according to the possible interactions: the $\pi-\pi$ interactions, hydrogen-bonding, and Van der Waals interactions $[54,55]$. The $\pi-\pi$ interactions are dominant mechanism on the graphene nanostructures. The $\pi-\pi$ interactions are also independent on the influence from environmental, like $\mathrm{pH}$, ionic concentration, temperature, and the concentration [56, 57]. Adsorption capacities' analysis in the $\mathrm{pH} 5$ ranged from 5 to 11 is depending on the $\mathrm{pH}$. Therefore, it suggests the physical adsorption through the $\pi-\pi$ stacking or hydrophobic effects between $\mathrm{CoOF}$ and AR18 [58]. However, FT-IR of the sample measured at the lowest $\mathrm{pH}$ suggests the presence of chemical bonding between CoOF and AR18.

\section{Reusability investigation of the carbonized CoOF}

The reusability and stability of the adsorbents is an essential aspect in terms of their industrial applications. Therefore, carbonized CoOF were analyzed in the repeatable AR18 adsorption-desorption process efficiency. Furthermore, chemical/physical changes in the structure (content of cobalt particles, their crystal structure, and changes in the size of carbon flakes) were also investigated. Figure 3a, b shows SEM images of the $\mathrm{CoOF}$ before and after dye adsorption. This analysis indicated that the adsorption of dye did not influence the morphology and the size of carbon flakes, as well as the size and distribution of cobalt nanoparticles on the carbon flakes. Figure $3 \mathrm{c}$ proves that the adsorption capacity was maintained in the second cycle $(87 \%$ of the dye was adsorbed). During the third adsorption cycle, nanomaterial adsorbed up to $40 \%$ of the dye. Due to the chemisorption mechanism, CoOF showed strong binding capability to AR18, since the release of dye was detected after the third cycle of adsorption. The saturated CoOF released up to $16 \%$ of the adsorbed dye during the single adsorption cycle. The nanocomposite was sodium hydroxide treated to restore its adsorption efficiency [59]. This process allowed observing $94 \%$ adsorption efficiency in the next cycle.

XRD analysis showed some differences in the CoOF chemical composition after the adsorption of AR18 (Fig. 3d). It showed the transformation of cobalt (II) oxide to the mixture of cobalt (II) and (III) oxides. The 

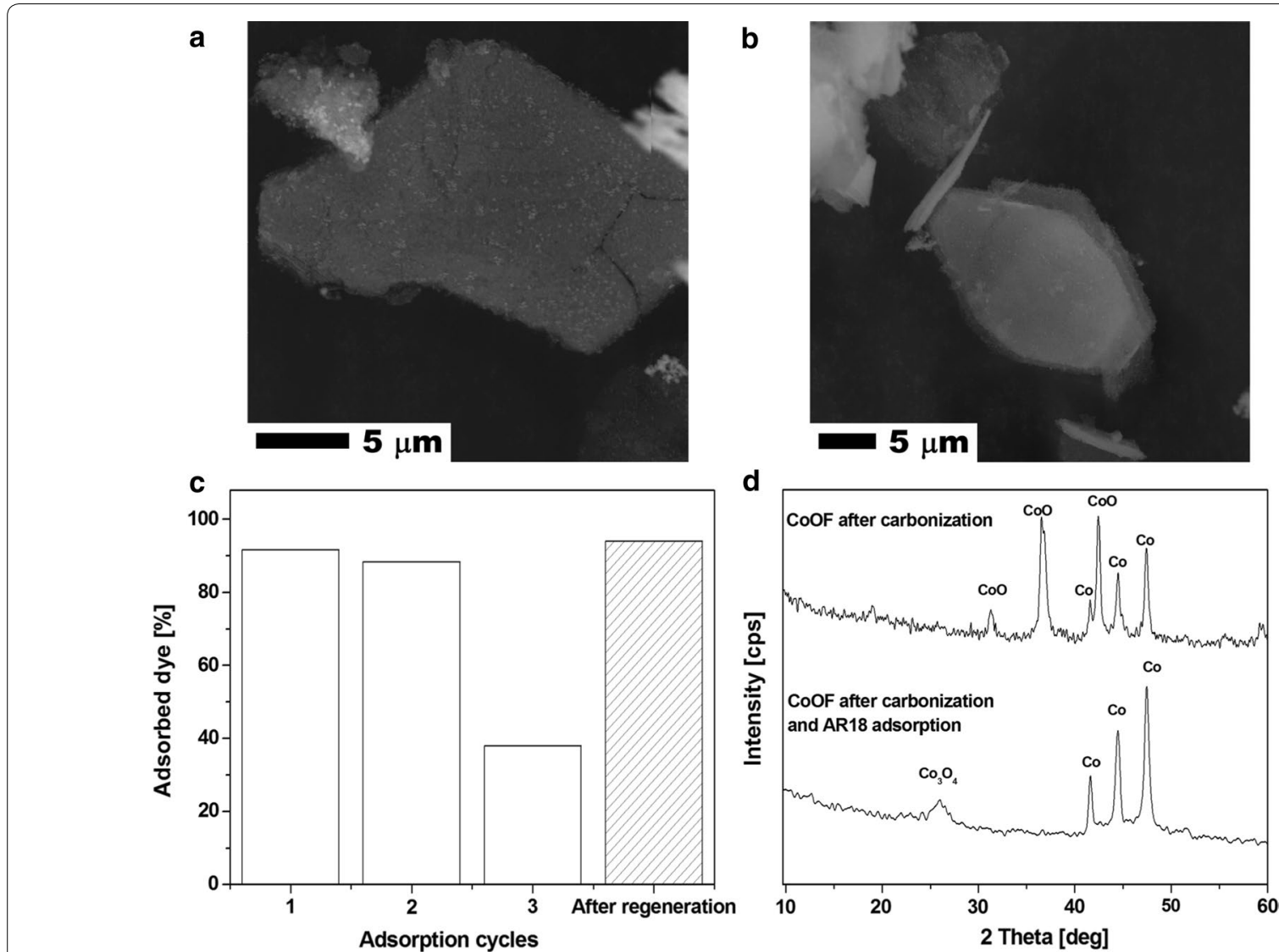

Fig. 3 SEM images of CoOF adsorbent (after purification) before adsorption (a) and after adsorption (b); the reusability of CoOF adsorbent (c); and XRD spectra of the CoOF before and after adsorption (d)

phenomenon was related to the oxidation of cobalt oxide in the aqueous solution, which was previously reported [60]. The oxidation of cobalt was caused by the water penetration into carbon layers [61], the physical disruption of carbon structure, or the extraction of cobalt spices on the surface of the carbonized CoOF.

\section{Cytotoxicity on microbial models}

MIC (minimal inhibitory concentration) observed for $P$. aeruginosa was $100 \mu \mathrm{g} \mathrm{mL}{ }^{-1}$, whereas it was not obtained for $S$. aureus (compare respiration). The viability of cells (respiration) measured in alamarBlue ${ }^{\circledR}$ assay confirmed results revealed in the OD measurements in the case of Gram-negative bacterium. Despite the reduction in OD in S. aureus culture with the highest concentration of carbonized $\mathrm{CoOF}$, the relative metabolic activity remained comparable to the control sample. The results are shown in Fig. 4. In Additional file 1: Figures S8 and S9, the comparison of the carbonized CoOF before and after acid purification, presenting the influence of trapping cobalt particles between graphene layers, is provided.

\section{Cell cytotoxicity}

The WST-1 test results showed a strong concentrationdependent cytotoxicity of free cobalt nanoparticles (Fig. 5). At the highest tested concentration $\left(55 \mu \mathrm{g} \mathrm{mL} \mathrm{L}^{-1}\right)$, cobalt nanoparticles decreased the viability of A375 cells to $9.28 \pm 4.87 \%$. The cobalt nanoparticles encapsulated inside the carbonized $\mathrm{CoOF}$ effectively prevented metal toxicity, even at the highest tested cobalt concentrations $\left(55 \mu \mathrm{g} \mathrm{mL}{ }^{-1}\right)$. The carbonized CoOF caused slight cytotoxicity-the cell viability dropped to $79.04 \pm 3.89 \%$.

\section{Waste reduction in the synthesis of CoOF by recycling organic substrates}

To reduce the amount of waste from the synthesis of carbonized CoOF, DMF from the previously used experiment was distilled. Furthermore, terephthalic acid was obtained from PET bottles.

SEM images of recycled CoOF show the same morphology as the pristine CoOF [see Fig. 6a (pristine) and Fig. $6 \mathrm{~b}$ (recycled)]. The structures received from both synthesis routes show characteristic shape and size of 

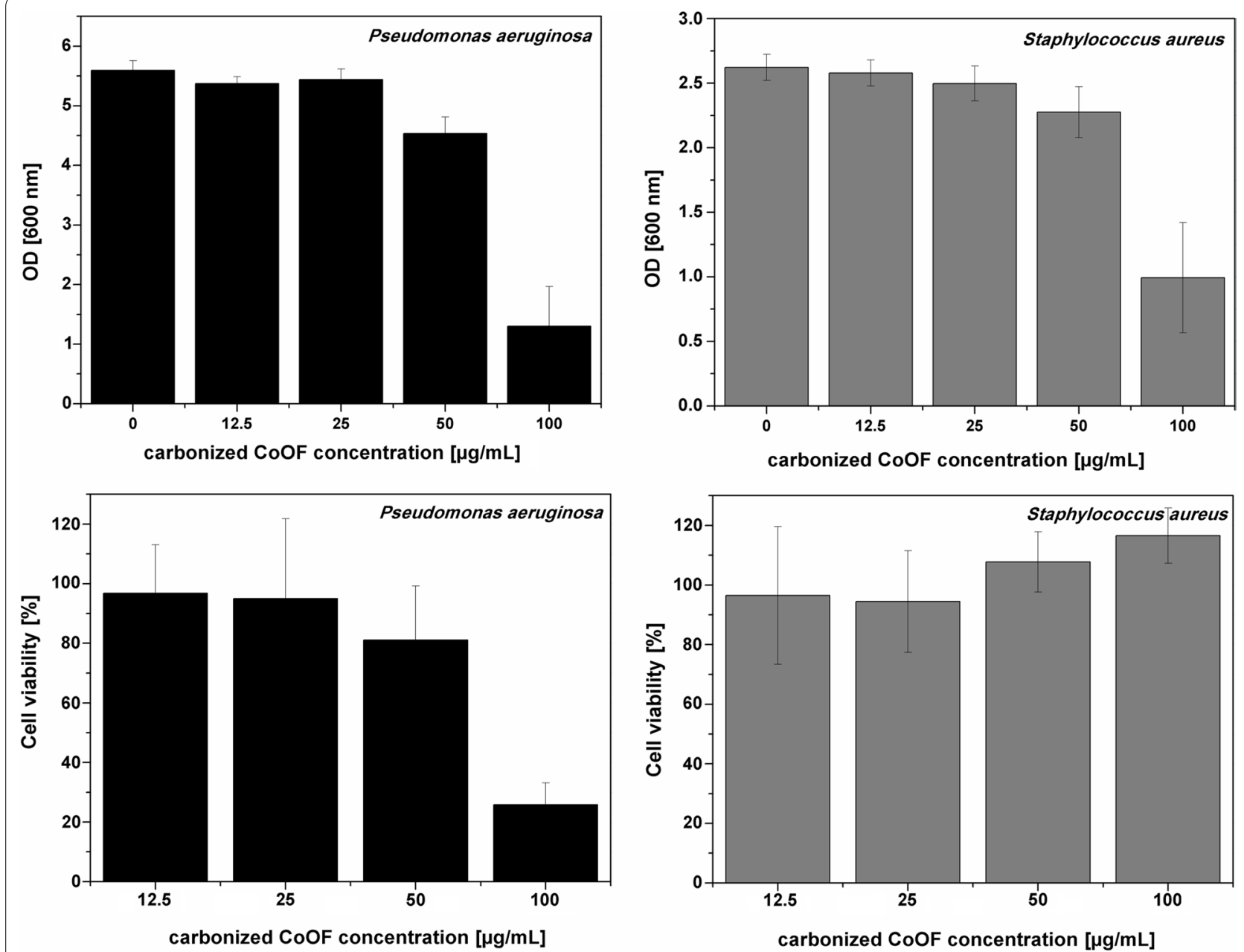

Fig. 4 Optical density (OD) of cultures after $24 \mathrm{~h}$ of incubation with nanomaterials in comparison to the control sample and viability of cells in alamarBlue ${ }^{\circledR}$ assay in relation to the control sample

cobalt based MOF-flat, hexagonal nanostructures. However, SEM image (Fig. 6c) shows that CoOF structures synthesized from the distilled DMF and recycled terephthalic acid exhibit smaller diameter in respect to the pristine material (the size distribution is provided in Additional file 1: Figure S6). The reported size of the CoOF from the recycled substrates was in the range of 1-5 $\mu \mathrm{m}$. The conclusions from microscopic observation were confirmed by the XRD analysis (Fig. 6d). The characteristic peaks corresponding to the terephthalic acid can be noticed in both samples. In the sample synthesized from the recycled substrates (DMF and terephthalic acid), some peaks from the unreacted terephthalic acid and PET can be observed.

The adsorption capacity of the structure obtained from recycled reagents was evaluated. The results are shown in Fig. 6d. Interestingly, the adsorptive capacity of this structure is very similar to the pristine one. Adsorption occurs a bit slower; however, the final concentration of the dye in the solution is nearly the same (pristine CoOF-2.6 $\mathrm{mg} \mathrm{L}^{-1}$, recycled CoOF $-3.4 \mathrm{mg} \mathrm{L}^{-1}$ ). The process for both samples proceeded according to the pseudo-second-order kinetic model (Additional file 1: Figure S10 and Table S4). Therefore, it is recognized that the material can be used in the adsorption process.

\section{Discussion}

Cobalt (in different compounds) is a well-known heavy metal causing cardiomyopathy [62], adverse pulmonary effects [63], carcinogenicity [64], and neurotoxicity [65]. The available in vitro data indicate that cobalt can induce cell death by apoptosis or necrosis [66], activation of caspases [67], and oxidative stress [68]. It should be pointed that mitochondria appear to be the main target of cobalt toxicity [69]. This nanomaterial can generate ROS (reactive oxygen species). It is already reported that 


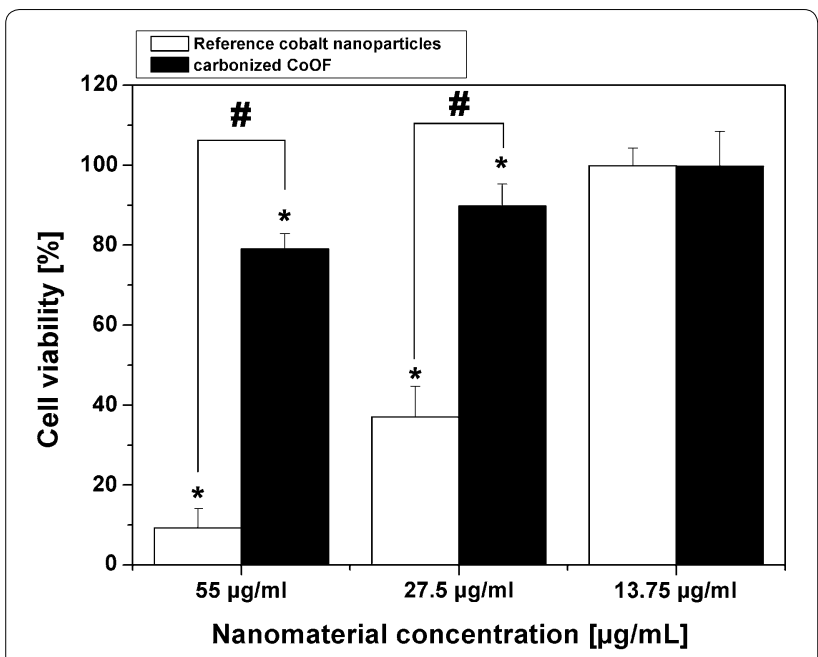

Fig. 5 The viability (\% of the control) of A375 cells after exposure to different concentrations of carbonized CoOF and cobalt nanoparticles as reference sample (at equal concentrations to carbonized COOF) measured by WST-1 assay; ${ }^{*} P<0.05$ statistical significance compared with the control cells; ${ }^{P} P<0.05$ statistical significance between cobalt nanoparticles as reference and cobalt contained in the carbonized CoOF
Gram-positive strain established a defence mechanism that can use ROS to upregulate cell's metabolism [70]. This underlines the susceptibility of $P$. aeruginosa and possible resistance of $S$. aureus to studied nanostructure. Our findings suggest that apart from decolourization properties, such nanostructures could be used also as component reducing Gram-negative bacteria in the filter. Nonetheless, in the present study on A375 cell by means of WST-1 viability assay, which is based on the measurement of mitochondrial activity, it is confirmed that carbon flakes prevent nanoCo toxicity. The encapsulation of toxic compounds in the protection layer is a promising strategy to obtain biocompatible and biologically useful particles. For example, silica was successfully used as a shell to coat Fe-based [71] and $\mathrm{Co} / \mathrm{Co}_{3} \mathrm{O}_{4}$-based [72] magnetic nanoparticles to reduce direct metal toxicities. Likewise, graphitic materials can be used as matrices for metals and metal oxides to improve their biocompatibility [73].

When the reusability of the adsorbents and the lack of potential cytotoxicity against living organisms are ensured, the essential aspect constitutes the industrial application of synthetized nanomaterials. The potential industrial synthesis of MOF structures depends on the cost, amount of the produced waste, and toxicity of the used substrates. Handling of toxic substrates and waste
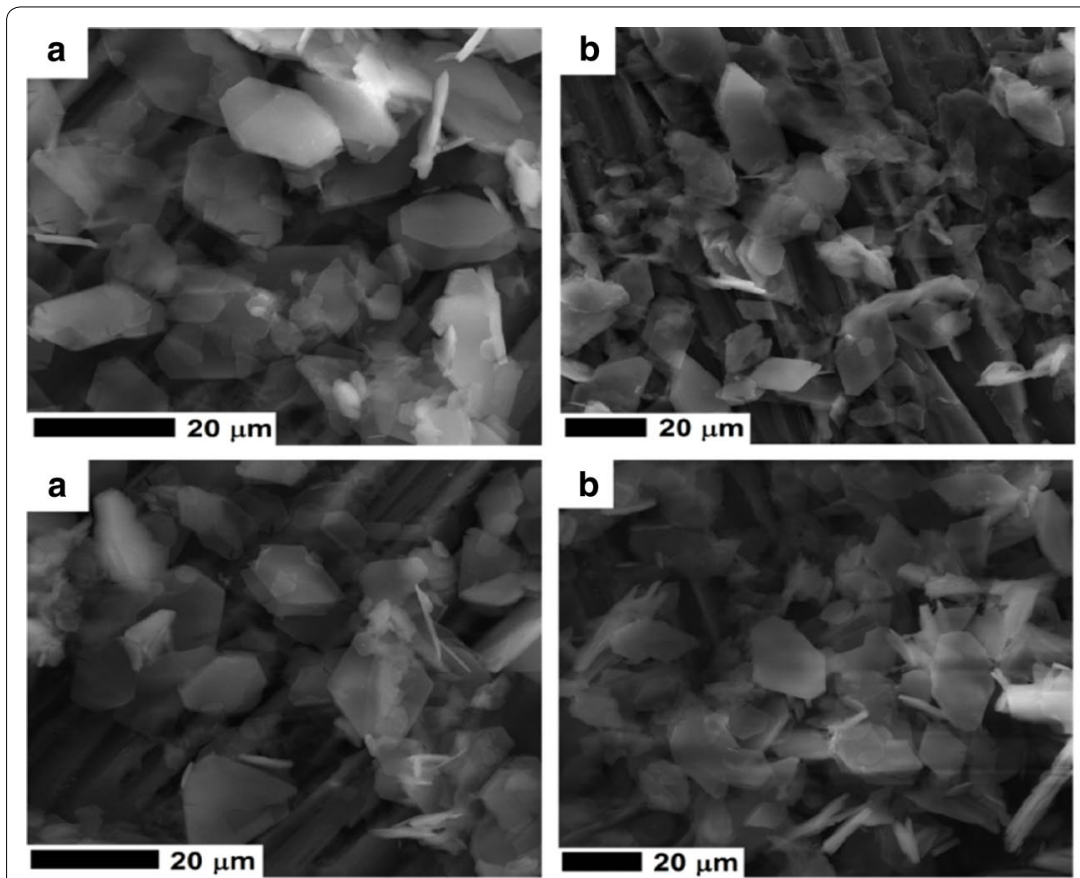
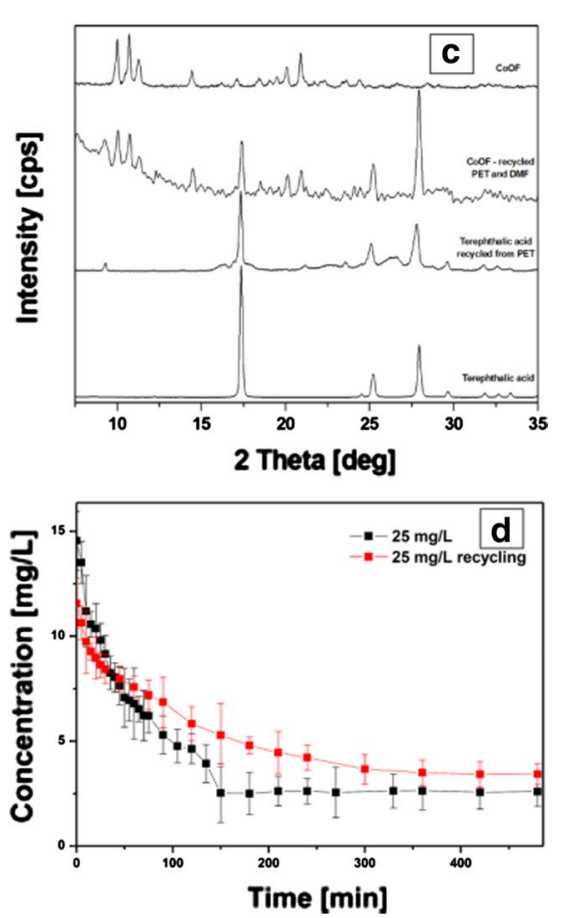

Fig. 6 SEM images of CoOF after synthesis from fresh (a) and recycled (b) substrates. XRD (c) of the pristine terephthalic acid and from hydrolysed PET bottles, and CoOF from pristine and recycled substrates. The effect of initial dye concentration on the adsorption capacity of the AR18 onto CoOF from pristine and recycled substrates $(\mathbf{d})$ 
will generate additional cost related to the environmental and health safety. Highly toxic, corrosion substrates, and waste are used in the industry to produce materials, but due to environmental concerns industrial company search for eco-friendly substitute. DMF used for synthesize MOF structures is regarded as toxic for natural environment and can cause birth defects in humans [74]. Non eco-friendly substitutes were reported and only potential reduction of the used DMF allows to minimize risk and synthesis/handling cost. As reported, to reuse of DMF, it should be separated from the unreacted substrates and obtained MOF by distillation. Second important substrate used in CoOF synthesis is organic ligand-terephthalic acid. As reported by Huang et al. [75] and Ren et al. [76], linker can be recovered from the PET waste, by hydrolysis and reused for synthesis of NTHU-2, NTHU3, MOF-5, MIL-53, MIL-101, and chromium-based MOF. The syntheses of MOF structures from the recycled terephthalic acid were confirmed by Deleu et al. [77]. Reducing the DMF waste and recycling terephthalic acid from PET waste allow not only to decrease the amount of toxic waste but also show the potential for industrial applications.

Azo-dyes (e.g., Acid Red 18) are one of the synthetic dyes that are used in many industries. The treatment and disposal of dye-contaminated wastewater is one of the most serious environmental problems. Intermediate products of azo-dyes are toxic, mutagenic, and carcinogenic to humans and aquatic life. For this reason, there are many reports about adsorption processes of this group of dyes. Table 1 lists the comparison of maximum monolayer adsorption capacity of AR 18 dye onto CoOF and other adsorbents. The maximum adsorption capacity $Q_{0}$ was $44.26 \mathrm{mg} \mathrm{g}^{-1}$ onto CoOF. In accordance with state of art on Acid Red 18 adsorption, the highest maximum

Table 1 Comparison of the maximum monolayer adsorption capacity $\left(Q_{0}\right)$ of AR 18 onto CoOF with others adsorbents reported in the literature

\begin{tabular}{|c|c|c|c|}
\hline Adsorbent & $Q_{0}\left(\mathrm{mg} \mathrm{g}^{-1}\right)$ & $\begin{array}{l}\text { Conditions } \\
(T)\left({ }^{\circ} \mathrm{C}\right)\end{array}$ & References \\
\hline Chitosan & 693.2 & 25 & [83] \\
\hline Nanochitosan & 243.92 & 25 & {$[78]$} \\
\hline Activated carbon & 3.91 & 20 & [84] \\
\hline Chitosan/carbon nanotube & 691.0 & 30 & [30] \\
\hline Activated charcoal & 10.75 & 20 & [79] \\
\hline $\begin{array}{l}\text { Chitosan-based semi-IPN } \\
\text { hydrogel }\end{array}$ & 358.42 & 25 & [85] \\
\hline Activated carbon & 34.247 & 30 & {$[86]$} \\
\hline Carbonaceous nanomaterial & 46.12 & 30 & {$[87]$} \\
\hline $\mathrm{CoOF}$ & 44.26 & 20 & This paper \\
\hline
\end{tabular}

monolayer adsorption capacity was observed for chitosan-based samples, $693 \mathrm{mg} \mathrm{g}^{-1}$ [78] and $691 \mathrm{mg} \mathrm{g}^{-1}$ [79]. According to Wong et al., the adsorption of the acid dyes on the chitosan occurs through the electrostatic attraction between two counter ions: the amino groups of chitosan and sulphate groups of acid dye [80]. Similar conclusions on the nature of AR 18 adsorption mechanism were reported by Shi Wang et al. [81]. As reported by Wong et al., the adsorption efficiency may mainly be attributed to the chemical structure and molecular size. Since larger dye ions, like AR 18, do not completely penetrate the adsorbent pore and preferentially adsorb on the outer surface [78]. Similar conclusion on the dyes adsorption on chitin was reported by McKay et al. [82]. Since the summarized reports (Table 1) shows that the presence of amino groups promotes the electrostatic interactions between AR 18 and adsorbent; this explains the lower adsorption capacity of CoOF than chitosan. Although CoOF adsorption capacity does not reach the highest values compared to other materials, it has other advantages. Due to the fact that the material contains cobalt, it makes it magnetic and can be easily separated from the solution. On the other hand, it can be used for adsorption many times, as well as we proved that the material can be prepared from recycled organic substrates. All these features promote $\mathrm{CoOF}$.

In the last several years, the number of reports on application of the magnetic graphene and graphene oxide nanocomposites increased extensively. The significance of graphene-based nanocomposites constantly rises due to the numerous advantages and potential applications, and a variety of magnetic nanoparticles that can be used to adjust nanocomposites to be suitable in the environmental protection. Throughout the twenty-first century, various hybrid nanostructures and nanocomposites of graphene with magnetic nanoparticles have been described. Metallic particles from the transition elements (e.g., Co [87]), metal oxides (e.g., $\mathrm{Fe}_{2} \mathrm{O}_{3}$ [88] and $\mathrm{Co}_{3} \mathrm{O}_{4}$ [89]), and different ferrites $\mathrm{MFe}_{2} \mathrm{O}_{4}[90]$ are usually used as magnetic nanoparticles. Many of these structures found their application as adsorbates [83]. The common technology of graphene-magnetic particle nanocomposite preparation is based on the chemical methods such as precipitation on the graphene surface from the precursor or chemical binding of the metallic/metal-oxide nanoparticles [91]. Second method reported by $\mathrm{Hu}$ et al. is based on the synthesis of graphene structures simultaneously with iron oxide particles, by thermal decomposition of glucose and Prussian blue [92]. A third alternative to obtain such hybrid nanocomposite is proposed in this study. Wide range of MOF structures give an opportunity to adjust the shape, structure, and chemical composition of the designed hybrid structures [93]. The carbonization 
of the CoOF allows obtaining hybrid structures with metal nanoparticles encapsulated by carbon structure [48]. Simultaneous carbonization and formation of the metal particles allow to decrease the number of stages required to produce the materials. Most of the graphene/ cobalt hybrid are studied as electrodes for the catalytic removal of dyes. In all of these structures, cobalt nanoparticles are located on the surface of graphene and are used as an electrode. Co-graphene hybrid proposed by Fei et al. showed higher catalytic efficiency in the degradation of Orange II than the reference Co [94]. Similar application in the catalytic decomposition of phenol was reported for the $\mathrm{Co}_{3} \mathrm{O}_{4}$ - graphene hybrid [95]. As shown in Table 1, the maximum monolayer CoOF adsorption capacity is consistent with the literature data. In our study, we show that Acid Red 18 chemically interacts in contrary to rhodamine B [50]. In this cationic dye, the physical interaction-by the hydrogen bondingwas detected [50]. Therefore, the adsorbed Acid Red 19 is attached stronger to the surface of the adsorbent and then rhodamine dye. Due to low surface area and not well-developed pore structure of CoOF, the amount of adsorbed dyes is not the highest one (in comparison to the reported data), but its magnetic behavior allows easier removal of the adsorbed dyes what is highly desired in practical applications.

Wang et al. reported not only an original hydrothermal reaction that resulted in the functionalization of oxidized graphite powder with cobalt nanoparticles of narrow size distribution, but also showed an efficient adsorption of Congo Red [96]. Furthermore, other proposed graphenecobalt hybrid structures were obtained in similar way, i.e., by placing metal/metal oxides on the surface of the graphene layers. In all of these studies, the cytotoxicity of cobalt nanoparticles has not been taken into account. The nanomaterials applied in the water treatment should perform the water purification without showing any toxicity to living organisms. Our studies showed that the encapsulation of cobalt nanoparticles not only prevented their negative influence on the biological models, but also protected them from the dissolution. Similar observation considering the protection of metal nanoparticles (from the metal reaction with the electrolyte) by the graphene coating was previously reported by Jiang et al. [97]. Moreover, the comparable effect of the protection/separation of metal [98] or other guest molecules (e.g., cytostatic drugs) from the environment was reported [99].

The possibility to reduce the amount of toxic waste from the CoOF production is another advantage of the carbonized CoOFs in application as dye adsorbers. As it was described above, DMF can be easily recovered by its distillation and recycled. Other reports similarly show the adsorption efficiency, potential application, and reusability of graphene-cobalt structures, although they do not consider the negative aspects (e.g., toxic waste or gases emission), or energy consumption during the production of materials. Current state of the art presents numerous methods of production of higher amount of the graphene-cobalt nanostructures. However, they still contain metal nanoparticles located on the surface of the graphene [53]. Such nanomaterials can pose a threat to health and the natural environment. The proposed route of CoOF synthesis provides a high-quality nanomaterial in the process that reduces the amount of waste and eliminates the toxicity of metal particles which are encapsulated between the carbon layers.

\section{Conclusions}

Flake-like structure with cobalt nanoparticles trapped between the carbon layers exhibits efficiency in the removal of Acid Red 18 (model anionic dye) that is used in the textile industry. The adsorption mechanism of anionic dye can be described by the pseudo-second-order kinetics and Langmuir isotherm. The evaluated thermodynamic parameters showed that the anionic dye adsorption was more favoured at lower temperatures and lower $\mathrm{pH}$. AR18 shows limited tendency to be released after the adsorption. Furthermore, carbonized CoOF can be efficiently reused in further adsorption studies. In the second adsorption cycle, $87 \%$ of the dye was absorbed, while in the third $40 \%$. After washing with sodium hydroxide, the material adsorbed again $94 \%$ of the dye again. Sandwich-like structure prevents cobalt nanoparticles to be released to the environment, where they could induce the toxicity. The material was tested on the selected human cells (A375) and reference micro-organisms (Gram-positive and Gram-negative). The location of the cobalt nanoparticles between the carbon flakes effectively limits their toxicity compared to the free metal nanoparticles. In addition, it was presented that CoOF can be synthesized from the recycled toxic DMF and terephthalic acid from the waste PET reducing the amounts of produced waste. The carbonized CoOF obtained from recycled substrates exhibits the same hexagonal shape with insignificantly smaller diameter and similar adsorption capacity.

\section{Supplementary information}

Supplementary information accompanies this paper at https://doi. org/10.1186/s12302-019-0242-9.

Additional file 1: Figure S1. The nitrogen adsorption isotherm of carbonized CoOF. All equations used for calculating kinetics and thermodynamics parameters of adsorption AR18 onto carbonized CoOF. Figure S2. The pseudo-second-order kinetics of adsorption AR18 onto carbonized and purified CoOF. Figure S3. Intraparticle diffusion model of the AR18 adsorption onto carbonized and purified CoOF. Table S1. Comparison of the pseudo-first-order and pseudo-second-order models for various 
initial concentrations of AR18. Figure S4. Langmuir-Freundlich adsorption isotherm of the AR18 onto carbonized and purified CoOF. Table S2. Langmuir- Freundlich parameters for the adsorption of the AR18 onto carbonized and purified CoOF. Figure S5. Effect of temperature on adsorption (A) of the AR18 onto carbonized and purified CoOF and Van't Hoffa isotherm (B). Table S3. Thermodynamic parameters for the adsorption of the AR18 onto carbonized and purified CoOF. Figure S6. FTIR spectrum of carbonized CoOF before and after dye adsorption at different $\mathrm{pH}$ (A) of the carbonized and acid purified CoOF after dye adsorption at $\mathrm{pH} 3$ and 5 (B). Figure S7. Size histogram of the CoOF synthesised from the pritine and recycled substrates. Figure $\mathbf{S 8}$. Optical Density (OD) of cultures after 24 hours of incubation with nanomaterials in comparison to the control sample. Figure $\mathbf{S 9}$. Viability of cells in alamarBlue ${ }^{\circledR}$ assay in relation to the control sample. Figure $\mathbf{S 1 0}$. The pseudo-second-order kinetics of adsorption AR18 (at concentration $25 \mathrm{mg} / \mathrm{L}$ ) onto carbonized and purified CoOF (with line) and CoOF from recycled substrates (red line). Table S4. Comparison of the pseudo-second-order models for carbonized and purified CoOF and CoOF from recycled substrates.

\section{Abbreviations}

MOFs, MOF: metal-organic frameworks; MOF-5: metal-organic framework $\mathrm{Zn}_{4} \mathrm{O}(\mathrm{BDC})_{3}$, where $\mathrm{BDC}^{2-}$ is 1,4-benzodicarboxylate; CoOF: Cobalt-based metal-organic framework; DMF: N,N-dimethyloformamide; AR18: Acid Red 18; PET: polyethylene terephthalate; OD: optical density; TGA: thermogravimetric analysis; MIC: minimal inhibitory concentration; XRD: X-ray diffraction; GO: graphene oxide.

\section{Acknowledgements}

The authors are grateful for the financial support of National Science Centre, Poland, within SONATA 2016/23/D/ST5/01683 and PRELUDIUM 2016/21/N/ ST8/02397. Biological studies were conducted as a part of a project "The search for novel methods of drug transport", No. WLA-127-02/S from Pomeranian Medical University in Szczecin. The authors are also grateful to Anna Zenderowska for assistance in synthesis and nanomaterials preparation.

\section{Authors' contributions}

All authors contributed on specific aspects of the manuscript. All authors read and approved the final manuscript. MT preformed the nanomaterials synthesis and adsorption experiments along with the kinetic models calculations. KC planed the experiment, preformed the nanomaterials analysis, and prepared first draft of the manuscript. MP planed and preformed experiment on the cells. AA planed and preformed experiment on the micro-organisms. PN, AA $M D$, and EM participated in the discussion of the results and manuscript correction. All authors read and approved the final manuscript.

\section{Funding}

This research was funded by the National Science Centre, Poland, within SONATA 2016/23/D/ST5/01683 and PRELUDIUM 2016/21/N/ST8/02397. Biological studies were conducted as a part of a project "The search for novel methods of drug transport", No. WLA-127-02/S/16 from Pomeranian Medical University in Szczecin.

\section{Availability of data and materials}

Not applicable.

\section{Ethics approval and consent to participate}

Not applicable.

\section{Consent for publication}

Not applicable.

\section{Competing interests}

The authors declare that they have no competing interests.

\section{Author details}

${ }^{1}$ Department of Nanomaterials Physicochemistry, Faculty of Chemical Technology and Engineering, West Pomeranian University of Technology, Al. Piastów 45, 70-311 Szczecin, Poland. ${ }^{2}$ Department of Experimental \& Clinical Pharmacology, Pomeranian Medical University, Powstancow Wlkp.
72, 70-111 Szczecin, Poland. ${ }^{3}$ Department of Immunology, Microbiology and Physiological Chemistry, Faculty of Biotechnology and Animal Husbandry, West Pomeranian University of Technology, Piastów Ave 45, 70-311 Szczecin, Poland. ${ }^{4}$ Building Materials and Construction Chemistry, Technische Universität Berlin, Gustav-Meyer-Allee 25, 13-355 Berlin, Germany.

Received: 8 April 2019 Accepted: 14 Auqust 2019

Published online: 10 September 2019

\section{References}

1. Seo JS, Whang D, Lee H, Jun SI, Oh J, Jeon YJ, Kim K (2000) A homochiral metal-organic porous material for enantioselective separation and catalysis. Nature 404:982-986

2. CookTR, Zheng YR, Stang PJ (2013) Metal-organic frameworks and self-assembled supramolecular coordination complexes: comparing and contrasting the design, synthesis, and functionality of metal-organic materials. Chem Rev 113:734-777

3. He Y, Zhou W, Qian G, Chen B (2014) Methane storage in metal-organic frameworks. Chem Soc Rev 43:5657-5678

4. Lim S, Suh K, Kim Y, Yoon M, Park H, Dybtsev DN, Kim K (2012) Porous carbon materials with a controllable surface area synthesized from metal-organic frameworks. Chem Commun 48:7447-7449

5. Kitagawa S, Kitaura R, Noro SI (2004) Functional porous coordination polymers. Angew Chem Int Ed 43:2334-2375

6. Corma A, García H, Llabrés FX, Xamena I (2010) Engineering metal organic frameworks for heterogeneous catalysis. Chem Rev 110:4606-4655

7. Chen B, Ockwig NW, Millward AR, Contreras DS, Yaghi OM (2005) High $\mathrm{H}_{2}$ adsorption in a microporous metal-organic framework with open metal sites. Angew Chem 117:4823-4827

8. Millward AR, Yaghi OM (2005) Metal-organic frameworks with exceptionally high capacity for storage of carbon dioxide at room temperature. J Am Chem Soc 127:17998-17999

9. Gu ZY, Yang CX, Chang N, Yan XP (2012) Metal-organic frameworks for analytical chemistry: from sample collection to chromatographic separation. Acc Chem Res 45:734-745

10. Della Rocca J, Liu D, Lin W (2011) Nanoscale metal-organic frameworks for biomedical imaging and drug delivery. Acc Chem Res 44:957-968

11. Huxford RC, Della Rocca J, Lin W (2010) Metal-organic frameworks as potential drug carriers. Curr Opin Chem Biol 14:262-268

12. Wang MS, Guo SP, Li Y, Cai LZ, Zou JP, Xu G, Zhou WW, Zheng FK, Guo GC (2009) A Direct white-light-emitting metal-organic framework with tunable yellow-to-white photoluminescence by variation of excitation light. J Am Chem Soc 131:13572-13573

13. Bin M, Andrew G, Ming Z, Chen ZH (2014) Synthesis, characterization, and dye sorption ability of carbon nanotube-biochar nanocomposites. Chem Eng J 236:39-46

14. Wang S, Wei C, Wang W, Li Q, Hao Z (2012) Synergistic and competitive adsorption of organic dyes on multiwalled carbon nanotubes. Chem Eng J 197:34-40

15. Sun Y, Wang G, Dong Q, Qian B, Meng Y, Qiu J (2014) Electrolysis removal of methyl orange dye from water by electrospun activated carbon fibers modified with carbon nanotubes. Chem Eng J 253:73-77

16. Dong Y, Lin H, Qu F (2012) Synthesis of ferromagnetic ordered mesoporous carbons for bulky dye molecules adsorption. Chem Eng J 193-194:169-177

17. Yu M, Li J, Wang L (2017) KOH-activated carbon aerogels derived from sodium carboxymethyl cellulose for high-performance supercapacitors and dye adsorption. Chem Eng J 310:300-306

18. Zheng X, Huang M, You Y, Fu X, Liu Y, Wen J (2018) One-pot synthesis of sandwich-like MgO@Carbon with enhanced sorption capacity of organic dye. Chem Eng J 334:1399-1409

19. Dai J, Xiao X, Duan S, Liu J, He J, Lei J, Wang L (2018) Synthesis of novel microporous nanocomposites of ZIF-8 on multiwalled carbon nanotubes for adsorptive removing benzoic acid from water. Chem Eng J 331:64-74

20. Li X, Liu Y, Zhang C, Wen T, Zhuang L, Wang X, Song G, Chen D, Ai Y, Hayat $\mathrm{T}$, Wang $X$ (2018) Porous $\mathrm{Fe}_{2} \mathrm{O}_{3}$ microcubes derived from metal organic frameworks for efficient elimination of organic pollutants and heavy metal ions. Chem Eng J 336:241-252 
21. Chen Q, Feng R, Xu J, Jia YY, Wang TT, Chang Z, Bu XH (2017) Kinetic and thermodynamic control of structure transformations in a family of cobalt(II)-organic frameworks. ACS Appl Mater Interfaces 9:35141-35149

22. Cendrowski K, Skumial P, Spera P, Mijowska E (2016) Thermally induced formation of zinc oxide nanostructures with tailoring morphology during metal organic framework (MOF-5) carbonization process. Mater Des 110:740-748

23. Zhao S, Yin H, Du L, He L, Zhao K, Chang L, Yin G, Zhao H, Liu S, Tang Z (2014) Carbonized nanoscale metal-organic frameworks as high performance electrocatalyst for oxygen reduction reaction. ACS Nano 8:12660-12668

24. Tan H, Ma C, Gao L, Li Q, Song Y, Xu F, Wang T, Wang L (2014) Metalorganic framework-derived copper nanoparticle@carbon nanocomposites as peroxidase mimics for colorimetric sensing of ascorbic acid. Chem Eur J 20:16377-16383

25. Xi K, Cao S, Peng X, Ducati C, Kumar RV, Cheetham AK (2013) Carbon with hierarchical pores from carbonized metal-organic frameworks for lithium sulphur batteries. Chem Commun 49:2192-2194

26. Xiao JD, Qiu LG, Jiang X, Zhu YJ, Ye S, Jiang X (2013) Magnetic porous carbons with high adsorption capacity synthesized by a microwaveenhanced high temperature ionothermal method from a Fe-based metal-organic framework. Carbon 59:372-382

27. Xia W, Mahmood A, Zou R, Xu Q (2015) Metal-organic frameworks and their derived nanostructures for electrochemical energy storage and conversion. Energy Environ Sci 8:1837-1866

28. Wong YC, Szeto YS, Cheung WH, McKay G (2004) Equilibrium studies for acid dye adsorption onto chitosan. Langmuir 39:693-702

29. Sarkar Shrabana, Banerjee Aparna, Halder Urmi, Biswas Raju, Bandopadhyay Rajib (2017) Degradation of synthetic azo dyes of textile industry: a sustainable approach using microbial enzymes. Water Conserv Sci Eng 2(4):121-131

30. Wang S, Zhai Y-Y, Gao Qiang, Luo W-J, Xia H, Zhou C-G (2014) Highly efficient removal of Acid Red 18 from aqueous solution by magnetically retrievable chitosan/carbon nanotube: batch study, isotherms, kinetics, and thermodynamics. J Chem Eng Data 59:39-51

31. Janveja B, Kant K, Sharma J (2008) A study of activated rice husk charcoal as an adsorbent of congo red dye present in textile industrial waste. J Punjab Acad Forensic Med Toxicol 8:12-15

32. Shi P, Su R, Wan F, Zhu M, Li D, Xu S (2012) $\mathrm{CO}_{3} \mathrm{O}_{4}$ nanocrystals on graphene oxide as a synergistic catalyst for degradation of Orange II in water by advanced oxidation technology based on sulfate radicals. Appl Catal B 123-124:265-272

33. Shi P, Su R, Zuh S, Zhu M, Li D, Xu S (2012) Supported cobalt oxide on graphene oxide: highly efficient catalysts for the removal of Orange II from water. J Hazard Mater. 229-230:331-339

34. Guivarch E, Trevin S, Lahitte C, Oturan MA (2003) Degradation of azo dyes in water by electro-Fenton process. Environ Chem Lett 1:38-44

35. Venkata Mohan S, Sailaja P, Srimurali M, Karthikeyan J (1999) Color removal of monoazo acid dye from aqueous solution by adsorption and chemical coagulation. Environ Eng Policy 1:149-154

36. Koyuncu I (2002) Reactive dye removal in dye/salt mixtures by nanofiltration membranes containing vinylsulphone dyes: effects of feed concentration and cross flow velocity. Desalination 143:243-253

37. Tehrani-Bagha AR, Mahmoodi NM, Menger FM (2010) Degradation of a persistent organic dye from colored textile wastewater by ozonation. Desalination 260:34-38

38. Purkait MK, DasGupta S, De S (2004) Removal of dye from wastewater using micellar-enhanced ultrafiltration and recovery of surfactant. Sep PurifTechnol 37:81-92

39. Ozcan A, Omeroglu C, Erdogan Y, Ozcan AS (2007) Modification of bentonite with a cationic surfactant: an adsorption study of textile dye Reactive Blue 19. J Hazard Mater 140:173-179

40. Al-Degs Y, Khraisheh MAM, Allen SJ, Ahmad MNA (2001) Sorption behavior of cationic and anionic dyes from aqueous solution on different types of activated carbons. Sep Sci Technol. 36:91-102

41. Leyssens L, Vinck B, Van Der Straeten C, Wuyts F, Maes L (2017) Cobalt toxicity in humans - a review of the potential sources and systemic health effects. Toxicology 387:43-56

42. Magaye R, Zhao J, Bowman L, Ding M (2012) Genotoxicity and carcinogenicity of cobalt-, nickel- and copper-based nanoparticles. Exp Ther Med 4(4):551-561
43. Srivastava N (2015) Interaction of cobalt nanoparticles with plants: a cytogenetical aspect. J Exp Nanosci 10:769-776

44. Abbas AS, Edwards C (1990) Effects of metals on Streptomyces coelicolor growth and actinorhodin production. Appl Environ Microbiol 56:675-680

45. Gikas $P(2008)$ Single and combined effects of nickel (Ni(II)) and cobalt (Co(II)) ions on activated sludge and on other aerobic microorganisms: a review. J Hazard Mater 159:187-203

46. Adiga PR, Sastry KS, Venkatasubramanyam V, Sarma PS (1961) Interrelationships in trace-element metabolism in Aspergillus niger. Biochem J 81:545-550

47. Al-Sarrani AQ (2001) Growth responses of Monoascus ruber teigh, to toxicity of certain metals in the presence of ascorbic acid. Egypt J Microbiol 36:147-160

48. Cendrowski K, Zenderowska A, Bieganska A, Mijowska E (2017) Graphene nanoflakes functionalized with cobalt/cobalt oxides formation during cobalt organic framework carbonization. Dalton Trans 46:7722-7732

49. Weidenthale C (2011) Pitfalls in the characterization of nanoporous and nanosized materials. Nanoscale 3:792-810

50. Barylak M, Cendrowski K, Mijowska E (2018) Application of carbonized metal-organic framework as highly efficient adsorbent of cationic dye. Ind Eng Chem Res 57(14):4867-4879

51. Gurses A, Dogar C, Yalcin M, Acikyildiz M, Bayrak R, Karaca S (2006) Adsorption kinetics of the cationic dye, methylene blue, onto clay. $J$ Hazard Mater 131:217-228

52. Wang S, Zhu Z (2007) H. Effects of acidic treatment of activated carbons on dye adsorption. Dyes Pigm 75:306-314

53. García ER, Medina RL, Lozano MM, Pérez IH, Valero MJ, Franco AM (2014) Adsorption of azo-dye Orange II from aqueous solutions using a metal-organic framework material: iron-benzenetricarboxylate. Materials 7:8037-8057

54. Sweetman MJ, May S, Mebberson N, Pendleton P, Vasilev K, Plush SE, Hayball JD (2017) Activated carbon, carbon nanotubes and graphene: materials and composites for advanced water purification. C 3:1-29

55. Li L, Quinlivan PA, Knappe DRU (2002) Effects of activated carbon surface chemistry and pore structure on the adsorption of organic contaminants from aqueous solution. Carbon 40:2085-2100

56. Xiao J, Lv W, Xie Z, Tan Y, Song Y, Zheng Q (2016) Environmentally friendly reduced graphene oxide as a broad-spectrum adsorbent for anionic and cationic dyes via p-p interactions. J Mater Chem A 4:12126-12135

57. Minitha CR, Lalitha M, Jeyachandran YL, Senthilkumar L, Kumar RTR (2017) Adsorption behaviour of reduced graphene oxide towards cationic and anionic dyes: co-action of electrostatic and $\pi-\pi$ interactions. Mater Chem Phys 194:243-252

58. Yan H, Wu H, Li K, Wang Y, Tao X, Yang H, Li A, Cheng R (2015) Influence of the surface structure of graphene oxide on the adsorption of aromatic organic compounds from water. ACS Appl Mater Interfaces 7:6690-6697

59. Lata S, Singh PK, Samadder SR (2015) Regeneration of adsorbents and recovery of heavy metals: a review. Int J Environ Sci Technol 12:1461-1478

60. Petitto SC, Marsh EM, Carson GA, Langell MA (2008) Cobalt oxide surface chemistry: the interaction of $\mathrm{CoO}\left(\begin{array}{lll}1 & 0 & 0\end{array}\right), \mathrm{Co}_{4} \mathrm{O}_{4}\left(\begin{array}{lll}1 & 1 & 0\end{array}\right)$ and $\mathrm{Co}_{3} \mathrm{O}_{4}\left(\begin{array}{lll}1 & 1 & 1\end{array}\right)$ with oxygen and water. J Mol Catal A Chem 281(1-2):49-58

61. Sun P, Zhu M, Wang K, Zhong M, Wei J, Wu D, Xu Z, Zhu H (2013) Selective ion penetration of graphene oxide membranes. ACS Nano 7:428-437

62. Kesteloot H, Roelandt J, Willems J, Claes JH, Joossens JV (1968) An enquiry into the role of cobalt in the heart disease of chronic beer drinkers. Circulation 37:854-864

63. Wehner AP, Busch RH, Olson RJ, Craig DK (1977) Chronic inhalation of cobalt oxide and cigarette smoke by hamsters. Am Ind Hyg Assoc J 38:338-346

64. Heath JC (1956) The production of malignant tumors by cobalt in the rat. Br J Cancer 10:668-673

65. Hasan M, Ali S, Anwar J (1980) Cobalt-induced depletion of dopamine, norepinephrine \& 5-hydroxytryptamine concentration in different regions of the rat brain. Indian J Exp Biol 18:1051-1053

66. Huk OL, Catelas I, Mwale F, Antoniou J, Zukor DJ, Petit A (2004) Induction of apoptosis and necrosis by metal ions in vitro. J Arthroplasty 19:84-87

67. Zou W, Zeng J, Zhuo M, Xu W, Sun L, Wang J, Liu X (2002) Involvement of caspase- 3 and p38 mitogen-activated protein kinase in cobalt chlorideinduced apoptosis in PC12 cells. J Neurosci Res 67:837-843 
68. Olivieri G, Hess C, Savaskan E, Ly C, Meier F, Baysang G, Brockhaus M, Müller-Spahn F (2001) Melatonin protects SHSY5Y neuroblastoma cells from cobalt-induced oxidative stress, neurotoxicity and increased betaamyloid secretion. J Pineal Res 31:320-325

69. Alarifi S, Ali D, Al Omar Suliman Y, Ahamed M, Siddiqui MA, Al-Khedhairy AA (2013) Oxidative stress contributes to cobalt oxide nanoparticlesinduced cytotoxicity and DNA damage in human hepatocarcinoma cells. Int J Nanomed 8:189-199

70. Lemire J, Alhasawi A, Appanna VP, Tharmalingam S, Appanna VD (2017) Metabolic defence against oxidative stress: the road less travelled so far. J Appl Microbiol 123:798-809

71. Yi DK, Selvan ST, Lee SS, Papaefthymiou GC, Kundaliya D, Ying JY (2005) Silica-coated nanocomposites of magnetic nanoparticles and quantum dots. J Am Chem Soc 127:4990-4991

72. Karovic O, Tonazzini I, Rebola N, Edstrom E, Lovdahl C, Fredholm BB, Dare E (2007) Toxic effects of cobalt in primary cultures of mouse astrocytes. Similarities with hypoxia and role of HIF-1alpha. Biochem Pharmacol 73:694-708

73. Hatamie S, Ahadian MM, Ghiass MA, Iraji ZA, Saber R, Parseh B, Oghabian MA, Shanehsazzadeh S (2016) Graphene/cobalt nanocarrier for hyperthermia therapy and MRI diagnosis. Colloids Surf B 146:271-279

74. Hurtt ME, Placke ME, Killinger JM, Singer AW, Kennedy GL Jr (1992) 13-week inhalation toxicity study of dimethylformamide (DMF) in cynomolgus monkeys. Fundam Appl Toxicol 18:596-601

75. Huang YT, Lai YL, Lin CH, Wang SL (2011) Direct use of waste PET as unfailing source of organic reagents in the synthesis of intrinsic white/yellow luminescent nanoporous zincophosphates. Green Chem 13:2000-2003

76. Ren J, Dyosiba X, Musyoka NM, Langmi HW, North BC, Mathe M, Onyango MS (2016) Green synthesis of chromium-based metal-organic framework (Cr-MOF) from waste polyethylene terephthalate (PET) bottles for hydrogen storage applications. Int J Hydrog Energy 41:18141-18146

77. Deleu WPR, Stassen I, Jonckheere D, Ameloot R, De Vos DE (2016) Waste PET (bottles) as a resource or substrate for MOF synthesis. J Mater Chem A 4:9519-9525

78. Cheung WH, Szeto YS, McKay G (2009) Enhancing the adsorption capacities of acid dyes by chitosan nano particles. Bioresour Technol 100:1143-1148

79. Naja Chaleshtori AA, Meghadddam FM, Sadeghi MM, Rahimi RR, Hemat S, Ahmadi AA (2017) Removal of Acid Red 18 (Azo-Dye) from aqueous solution by adsorption onto activated charcoal prepared from almond shell. J Environ Sci Manag 20:9-16

80. Wong YC, Szeto YS, Cheung WH, McKay G (2003) Equilibrium studies for acid dye adsorption onto chitosan. Langmuir 19:7888-7894

81. Wang S, Li H (2007) Kinetic modelling and mechanism of dye adsorption on unburned carbon. Dyes Pigments 72:308-314

82. McKay G, Blair HS, Gardner JR (1982) Adsorption of dyes on chitin. Equilibrium studies. J Appl Polym Sci 27:3043-3057

83. Wong YC, Szeto YS, Cheung WH, McKay G (2004) Adsorption of acid dyes on chitosan-equilibrium isotherm analyses. Process Biochem 39:693-702

84. Shokoohi R, Vatanpoor V, Zarrabi M, Vatani A (2010) Adsorption of Acid Red 18 (Ar18) by activated carbon from poplar wood - a kinetic and equilibrium study. E-J Chem 7:65-72
85. Zhao S, Zhou F, Li L, Cao M, Zuo D, Liu H (2012) Removal of anionic dyes from aqueous solutions by adsorption of chitosan-based semi-IPN hydrogel composites. Compos Part B 43:1570-1578

86. Saratale RG, Sivapathan SS, Jung WJ, Kim Hee Y, Saratale GD, Kim DS (2016) Preparation of activated carbons from peach stone by H4P2O7 activation and its application for the removal of Acid Red 18 and dye containing wastewater. J Environ Sci Health Part A 51:164-177

87. Liu GJ, Fan LQ, Yu FD, Wu JH, Liu L, Qiu ZY, Liu Q (2013) Facile one-step hydrothermal synthesis of reduced graphene oxide/ $\mathrm{CO}_{3} \mathrm{O}_{4}$ composites for supercapacitors. J Mater Sci 48:8463-8470

88. Zou Y, Kan J, Wang Y (2011) $\mathrm{Fe}_{2} \mathrm{O}_{3}$-graphene rice-on-sheet nanocomposite for high and fast lithium ion storage. J Phys Chem C 115:20747-20753

89. Xiao J, Xu G, Sun SG, Yan S (2013) $\mathrm{MFe}_{2} \mathrm{O}_{4}$ and MFe@Oxide core-shell nanoparticles anchored on $\mathrm{N}$-doped graphene sheets for synergistically enhancing lithium storage performance and electrocatalytic activity for oxygen reduction reactions. Part Part Syst Charact 30:893-904

90. Khan NA, Hasan Z, Jhung SH (2013) Adsorptive removal of hazardous materials using metal-organic frameworks (MOFs): a review. J Hazard Mater 244-245:444-456

91. He F, Fan J, Ma D, Zhang L, Leung C, Chan HL (2010) The attachment of $\mathrm{Fe}_{3} \mathrm{O}_{4}$ nanoparticles to graphene oxide by covalent bonding. Carbon 48:3139-3144

92. Hu J, Zheng J, Tian L, Duan Y, Lin L, Cui S, Peng H, Liu T, Guo H, Wang X,

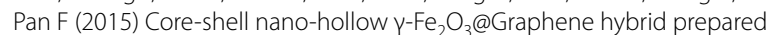
through the Kirkendall process as high performance anode materials for lithium ion battery. Chem Commun 51:7855-7858

93. Tang J, Yamauchi Y (2016) Carbon materials: MOF morphologies in control. Nat Chem 8:638-639

94. Fei H, Dong J, Arellano-Jiménez MJ, Ye G, Kim ND, Samuel ELG, Peng Z, Zhu Z, Qin F, Bao J, Yacaman MJ, Ajayan PM, Chen D, Tour JM (2015) Atomic cobalt on nitrogen-doped graphene for hydrogen generation. Nat Commun 6:8668

95. Yao Y, Yang Z, Sun $\mathrm{H}$, Wang $\mathrm{S}(2012)$ Hydrothermal synthesis of $\mathrm{Co}_{3} \mathrm{O}_{4}-$ graphene for heterogeneous activation of peroxymonosulfate for decomposition of phenol. Ind Eng Chem Res 51:14958-14965

96. Wang L, Li J, Mao C, Zhang L, Zhao L, Jiang Q (2013) Facile preparation of a cobalt hybrid/graphene nanocomposite by in situ chemical reduction: high lithium storage capacity and highly efficient removal of Congo red. Dalton Trans 42:8070-8077

97. Jiang X, Yang X, Zhu Y, Yao Y, Zhao P, Li C (2015) Graphene/carbon-coated $\mathrm{Fe}_{3} \mathrm{O}_{4}$ nanoparticle hybrids for enhanced lithium storage. J Mater Chem A 3:2361-2369

98. Singh R, Torti SV (2013) Carbon nanotubes in hyperthermia therapy. Adv Drug Deliv Rev 65:2045-2060

99. Liu Z, Tabakman S, Welsher K, Dai H (2009) Carbon nanotubes in biology and medicine: in vitro and in vivo detection, imaging and drug delivery. Nano Res 2:85-120

\section{Publisher's Note}

Springer Nature remains neutral with regard to jurisdictional claims in published maps and institutional affiliations.

\section{Submit your manuscript to a SpringerOpen ${ }^{\odot}$ journal and benefit from:}

- Convenient online submission

- Rigorous peer review

- Open access: articles freely available online

- High visibility within the field

- Retaining the copyright to your article

Submit your next manuscript at $\boldsymbol{\nabla}$ springeropen.com 